\title{
Pathogenic Antibodies Inhibit the Binding of Apolipoproteins to Megalin/gp330 in Passive Heymann Nephritis
}

\author{
Dontscho Kerjaschki, ${ }^{\star}$ Markus Exner, ${ }^{\star}$ Robert Ullrich, ${ }^{\star}$ Martin Susani, ${ }^{*}$ Linda K. Curtiss, Joseph L. Witztum, \\ Marilyn Gist Farquhar, ${ }^{\ddagger}$ and Robert A. Orlando ${ }^{\ddagger}$ \\ * Section of Ultrastructural Pathology, Department of Clinical Pathology, University of Vienna, A-1090 Vienna, Austria; ${ }^{\ddagger}$ Division of \\ Cellular and Molecular Medicine and Department of Pathology, and ${ }^{\S}$ Division of Endocrinology and Metabolism, Department of Internal

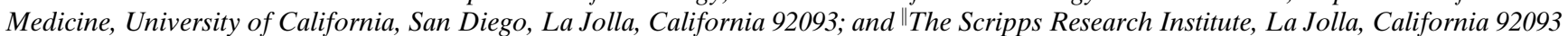

\begin{abstract}
Megalin/gp330 is an endocytic receptor that internalizes multiple ligands including apolipoproteins $\mathrm{E}$ (apo E) and B100 (apo B). Megalin is the main antigenic target in passive Heymann nephritis ( $\mathrm{pHN}$ ), where it binds circulating autoantibodies leading to the formation of subepithelial immune deposits (ID)— the hallmark of $\mathrm{pHN}$. Apo $\mathrm{E}$ and apo $B$ were found recently to accumulate within these IDs, and evidence was provided that their lipids may undergo peroxidation, causing glomerular basement membrane damage and proteinuria. Here we investigated if ID-forming antimegalin IgG can inhibit the binding and internalization of apo E- $\beta$ VLDL (very low density lipoprotein) by megalin, and lead to their accumulation within IDs. By immunoelectron microscopy, apo $\mathrm{E}$ and apo $\mathrm{B}$ were detected in clathrincoated pits and multivesicular bodies of podocytes in control rats, suggesting that the uptake of lipoproteins is a constitutive function of the glomerular epithelium. When pHN was induced by intravenous injection of antimegalin IgG, apo E and apo $\mathrm{B}$ were found within IDs by immunofluorescence and immunoelectron microscopy. Bound antibodies eluted from glomeruli of rats with $\mathrm{pHN}$ were found to inhibit the binding and internalization of apo E-enriched $\beta$ VLDL by megalin. These results indicate that $\mathrm{pHN}$-inducing antimegalin IgG is capable of interfering with the uptake of lipoproteins by megalin in vivo during the formation of IDs. (J. Clin. Invest. 1997. 100:2303-2309.) Key words: apolipoprotein • megalin gp330 - Heymann nephritis • lipid peroxidation
\end{abstract}

\section{Introduction}

Severe proteinuria in patients with membranous nephropathy causes the nephrotic syndrome with hyperlipidemia, accelerated atherosclerosis, and increased probability of thrombus formation (1). Moreover, high proteinuria is directly related to the development of chronic renal failure (2). Because direct

Address correspondence to Dr. Dontscho Kerjaschki, Department of Clinical Pathology, University of Vienna, Währinger Gürtel 18-20, A-1090 Vienna, Austria. Phone: 43-1-40400-5176; FAX: 43-1-404005193; E-mail: dontscho.kerjaschki@akh-wien.ac.at

Received for publication 23 December 1996 and accepted in revised form 27 August 1997.

J. Clin. Invest.

(C) The American Society for Clinical Investigation, Inc. 0021-9738/97/11/2303/07 \$2.00

Volume 100, Number 9, November 1997, 2303-2309

http://www.jci.org analysis of the molecular pathogenesis of proteinuria is difficult to perform in human patients, we and others study an experimental rat model of human membranous nephropathy called Heymann nephritis $(\mathrm{HN}) .{ }^{1} \mathrm{HN}$ is characterized by the formation of subepithelial immune deposits (ID) in the glomerular basement membrane (GBM) and by the development of proteinuria (3).

Considerable progress has been made in the analysis of the pathogenic mechanisms of ID formation in $\mathrm{HN}$ (4) and, to a lesser extent, of GBM damage and proteinuria (5). The endogenous antigenic target of $\mathrm{HN}$ was identified as a large membrane glycoprotein called megalin (originally named gp330) (6). Megalin is a multiligand receptor of the LDL-receptor gene family $(7,8)$. Of the various ligands that have been identified for megalin, apolipoproteins B100 (apo B) and E (apo E) $(9,10)$ are of particular interest for the pathogenesis of passive $\mathrm{HN}$ ( $\mathrm{pHN}$ ) since they were localized recently within IDs of proteinuric rats with $\mathrm{pHN}$ (11). Moreover, evidence was provided that apo B was modified locally by lipid peroxidation (LPO) (11). LPO is a major cause of GBM damage and proteinuria (12), and apo E-enriched $\beta$ VLDL may therefore provide polyunsaturated fatty acids to fuel this reaction.

These findings have raised questions about the molecular mechanisms leading to the accumulation of lipoproteins within IDs. In this study, we show that antimegalin antibodies eluted from glomeruli of $\mathrm{pHN}$ rats inhibit binding and uptake of apos by megalin. Our results suggest that during the induction of pHN, antimegalin antibodies bind to the receptor on the basal surface of podocytes and inhibit the endocytic clearance of apos from the glomerular filtrate. The inhibition of apo internalization leads to their accumulation within IDs of $\mathrm{pHN}$ rats, and may provide the necessary lipid environment for peroxidation and GBM damage.

\section{Methods}

Antibodies. Affinity-purified sheep antimegalin IgG was prepared from anti-Fx1A IgG (provided by Dr. W.G. Couser, University of Washington, Seattle, WA) by absorption onto a megalin/ $\mathrm{CNBr}$ Sepharose 4B column. Rabbit antibodies to purified rat megalin (antimegalin, 070) (13) or to renal tubular microvilli (14) were prepared as described (15). Mouse mAb (20B) was raised against purified rat megalin (16). Mouse monoclonal IgGs specific for rat apo E and apo $\mathrm{B}$ were prepared and used as described (11). Briefly, mouse monoclonal IgG specific for rat apo B was raised against rat apo B purified by precipitation from isolated LDL fractions. Monoclonal anti-apo $\mathrm{E}$ $\mathrm{IgG}$ was produced by immunizing mice with isolated rat HDLs. The antibodies were screened and selected by immunoblotting purified apo B and apo E. FITC-conjugated rabbit anti-sheep $\mathrm{F}\left(\mathrm{ab}^{\prime}\right)_{2}$ fragments and FITC-conjugated goat anti-mouse IgG were from DAKO-

1. Abbreviations used in this paper: $\mathrm{HN}$, Heymann nephritis; ID, immune deposit; LPO, lipid peroxidation; $\mathrm{pHN}$, passive HN. 
PATTS (Copenhagen, Denmark). $10 \mathrm{~nm}$ gold-conjugated rabbit anti-sheep and sheep anti-mouse IgG were from Amersham International (Little Chalfont, UK).

Purification of apo E-enriched $\beta V L D L$. Blood was collected from cholesterol-fed New Zealand White rabbits and supplemented with $\mathrm{Na}_{2}$ EDTA to a final concentration of $1 \mathrm{mg} / \mathrm{ml}$. Plasma was cleared by centrifugation $(500 \mathrm{~g})$ for $20 \mathrm{~min}$ at $10^{\circ} \mathrm{C}$. Plasma was then added to a centrifuge tube (Ultra Clear; Beckman Instruments, Inc., Fullerton, $\mathrm{CA}$ ), overlaid with an equal volume of $0.9 \% \mathrm{NaCl}$, and centrifuged $(25,000 \mathrm{~g})$ for $20 \mathrm{~min}$ at $20^{\circ} \mathrm{C}$. The top chylomicron layer was removed and replaced with an equal volume of $0.9 \% \mathrm{NaCl}$, and centrifuged $(25,000 \mathrm{~g})$ for $20 \mathrm{~min}$ at $20^{\circ} \mathrm{C}$. Residual chylomicron remnants were then removed, and the remaining material was centrifuged $(25,000 \mathrm{~g})$ for $16 \mathrm{~h}$ at $20^{\circ} \mathrm{C}$. The $\beta$ VLDL layer was removed from the top, sterilefiltered, and protein concentration was determined by the BCA protein assay according to the manufacturer's instructions (Pierce Chemical Co., Rockford, IL). The apo E-enriched $\beta$ VLDL fraction (Fig. 1, lane $B$ ) consisted of apo $\mathrm{E}$ (molecular mass $\sim 34 \mathrm{kD}$ ) and apo $\mathrm{B}$ (molecular mass $\sim 515 \mathrm{kD}$ ).

Megalin purification and radioiodination. Megalin was purified by $\mathrm{mAb}$ affinity chromatography as previously described (17) and radioiodinated using the Iodo-Bead method according to the manufacturer's instructions (Pierce Chemical Co.). Megalin migrated as a single intact band before (Fig. 1, lane $C$ ) and after (Fig. 1, lane $D$ ) labeling with ${ }^{125} \mathrm{I}$.

Induction of $p H N$. 250-g male Sprague-Dawley rats were injected intravenously with $100 \mu \mathrm{g}$ affinity-purified sheep antimegalin IgG and killed after 3 or $6 \mathrm{~d}$. Other rats were injected with $10-15 \mathrm{mg}$ rabbit $\operatorname{IgG}$ fractions raised against rat microvillar fractions (18), or purified megalin (19). Use of experimental animals was authorized by the Austrian Ministry of Science.

Glomerular eluates. IgG was eluted from isolated glomeruli or from homogenates of renal cortex of rats with $\mathrm{pHN}$ with $20 \mathrm{mM}$ citrate buffer, $\mathrm{pH} 2.8$, as described (15). IgG fractions were prepared by protein $\mathrm{A}$ or protein $\mathrm{G}$ affinity chromatography (Pharmacia Biotech AB, Uppsala, Sweden). The titers of IgGs eluted from glomeruli of pHN rats were determined by indirect immunofluorescence on cryostat sections of rat kidney. Activities were then normalized by dilution to give equal titers. Protein concentrations of eluted $\mathrm{IgG}$ were determined by ELISA (see below). The eluted glomerular IgG of 3or 6-d pHN rats was analyzed by SDS-PAGE under reducing conditions followed by silver staining, and found to contain only IgG light $(\sim 25 \mathrm{kD})$ and heavy $(\sim 55 \mathrm{kD})$ chains (Fig. 1, lane $A)$.

Determination of IgG concentrations by ELISA. Wells of microtiter plates (Corning Glassworks, Corning, NY) were coated by incubating with affinity-purified $\mathrm{F}\left(\mathrm{ab}^{\prime}\right)_{2}$ fragments of goat anti-rabbit or

A B C D

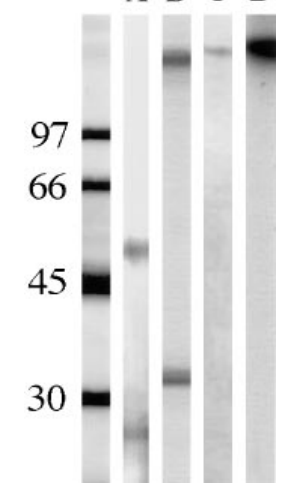

Figure 1. Analysis of reagents used for the solid-phase binding assay. Samples were mixed with Laemmli buffer containing $4 \%$ $\beta$-mercaptoethanol and separated by SDSPAGE on $5-15 \%$ gradient gels, and proteins were detected by silver staining (lane $A$ ) or with Coomassie blue (lanes $B$ and $C$ ), or processed for autoradiography (lane $D$ ). Lane $A$, Affinity-purified eluate prepared from isolated glomeruli of rats injected $3 \mathrm{~d}$ before with sheep antimegalin IgG. Only heavy (molecular mass $\sim 55 \mathrm{kD}$ ) and light (molecular mass $\sim 25 \mathrm{kD}$ ) chains of IgG are detected. Lane $B$, Rabbit apo E-enriched $\beta$ VLDL contains only apo $E$ (molecular mass $\sim 34 \mathrm{kD}$ ) and apo B (molecular mass $\sim 515 \mathrm{kD}$ ). Lane $C$, Affinity-purified megalin from rat renal microvilli (molecular mass $\sim 600 \mathrm{kD}$ ). Lane $D$, Same preparation of megalin as in $C$, after radioiodination, demonstrating that there is no degradation of megalin as a result of the radiolabeling procedure. anti-sheep IgG (Accurate Chemical and Science Corp., Westbury, $\mathrm{NY}, 5 \mu \mathrm{g} / \mathrm{ml}$ ) for $3 \mathrm{~h}$ at $20^{\circ} \mathrm{C}$. Nonspecific sites were blocked with $2.5 \%$ BSA in PBS for $1 \mathrm{~h}$ at $20^{\circ} \mathrm{C}$. Wells were rinsed with PBS containing $0.05 \%$ Tween 20 , and incubated with varying concentrations of glomerular eluted $\mathrm{IgG}$ for $1 \mathrm{~h}$ at $37^{\circ} \mathrm{C}$. After rinsing wells three times with PBS containing $0.05 \%$ Tween 20 , wells were incubated with peroxidase-conjugated affinity-purified goat anti-rabbit or antisheep IgG F $\left(\mathrm{ab}^{\prime}\right)_{2}$ (Accurate Chemical and Science Corp., $5 \mu \mathrm{g} / \mathrm{ml}$ ) for $1 \mathrm{~h}$ at $37^{\circ} \mathrm{C}$. After washing, bound peroxidase-conjugated antibodies were detected by incubating with DAB $(0.04 \%)$ in $20 \mathrm{mM}$ citrate buffer, $\mathrm{pH}$ 5.0. Color development was stopped by the addition of $8 \mathrm{~N}$ sulphuric acid and quantitated using an ELISA plate reader (Dynatech Laboratories, Inc., Chantilly, VA). Glomerular eluted IgG was quantitated by comparing directly to a standard curve generated in parallel using known concentrations of rabbit or sheep IgG.

Immunofluorescence. Kidneys of normal rats and of rats with 3 and $6 \mathrm{~d}$ pHN were perfused with MEM for 5 min. The cortex was minced, and small pieces of cortex were snap-frozen in liquid $\mathrm{N}_{2}$. Cryostat sections $(4 \mu \mathrm{m})$ were prepared, dipped in $-20^{\circ} \mathrm{C}$ acetone, and air dried. Some sections were incubated directly with FITC-conjugated anti-sheep $\mathrm{IgG}$, and others were incubated with murine mAbs directed against rat apo E or apo B $(10 \mu \mathrm{g} / \mathrm{ml})$ followed by FITC-conjugated goat anti-mouse IgG (11). As controls, primary IgGs were omitted or replaced by irrelevant mAbs. Micrographs were taken on a microscope equipped for epifluorescence (Axiophot; Carl Zeiss, Oberkochen, Germany).

Immunoelectron microscopy. Kidneys of rats injected with antimegalin $\operatorname{IgG}$ were flushed with MEM followed by perfusions with freshly prepared $4 \%$ formaldehyde in PBS. Fixation was continued for $6 \mathrm{~h}$ at $20^{\circ} \mathrm{C}$, followed by embedding in Lowicryl K4M (Chemische Werke LOWI, Waldkraiburg, Germany) (20). Ultrathin sections were blocked with $1 \%$ ovalbumin in PBS for $1 \mathrm{~h}$, followed by incubation with rabbit antimegalin $\mathrm{IgG}$ or with the murine $\mathrm{mAbs}$ against rat apo $\mathrm{E}$ or apo $\mathrm{B}(\sim 50 \mu \mathrm{g} / \mathrm{ml})$ and an anti-mouse 10 -nm gold conjugate (1:50). Sections were stained with lead citrate (21).

Solid-phase binding assays. Wells of microtiter plates (Falcon Labware, Becton Dickinson, Oxnard, CA) were coated for $16 \mathrm{~h}$ at $4^{\circ} \mathrm{C}$ with $100 \mu \mathrm{g} / \mathrm{ml}$ of apo E-enriched $\beta$ VLDL in $20 \mathrm{mM}$ Hepes, $\mathrm{pH}$ 7.4, $150 \mathrm{mM} \mathrm{NaCl}, 2 \mathrm{mM} \mathrm{CaCl}_{2}$ (buffer A). Wells were rinsed three times with buffer $\mathrm{A}$, and nonspecific sites were blocked by incubation with buffer A containing 3\% BSA for $1 \mathrm{~h}$ at $23^{\circ} \mathrm{C}$. The immobilized apo E- $\beta$ VLDL was then incubated with ${ }^{125} \mathrm{I}$-megalin $\left(4 \times 10^{5} \mathrm{cpm}, 1.5 \mu \mathrm{g} /\right.$ $\mathrm{ml}$ ) in buffer A containing 3\% BSA for $3 \mathrm{~h}$ at $23^{\circ} \mathrm{C}$ in the presence or absence of the following reagents: apo E- $\beta$ VLDL $(10 \mu \mathrm{g} / \mathrm{ml})$, sheep antimegalin $(10 \mu \mathrm{g} / \mathrm{ml})$, rabbit antimegalin $(30 \mu \mathrm{g} / \mathrm{ml})$, or glomerular eluates from rats with pHN induced with either sheep $(10 \mu \mathrm{g} / \mathrm{ml})$, or rabbit antimegalin $(3 \mu \mathrm{g} / \mathrm{ml})$, rabbit antimicrovillar IgG from 3-d $\mathrm{pHN}$ rats $(20 \mu \mathrm{g} / \mathrm{ml})$, rabbit antimicrovillar IgG glomerular eluate from 6 -d pHN rats $(20 \mu \mathrm{g} / \mathrm{ml})$, and monoclonal antimegalin $20 \mathrm{~B}(24 \mu \mathrm{g} / \mathrm{ml})$. Wells were rinsed three times with buffer $\mathrm{A}$, and bound ${ }^{125} \mathrm{I}$-megalin was released by the addition of $2 \mathrm{~N} \mathrm{NaOH}$ and quantitated in a gamma counter (5500B; Beckman Instruments, Inc.). SD and statistical significances of the mean values of replicate points were calculated by the Student's $t$ test.

L2 cell internalization and degradation assay. L2 rat yolk sac carcinoma cells, which are known to express megalin $(13,22)$, were grown to confluency on $1 \%$ gelatin-coated cell culture plates in DME supplemented with $10 \%$ FCS, $100 \mu \mathrm{g} / \mathrm{ml}$ streptomycin sulfate, and $100 \mathrm{U} / \mathrm{ml}$ penicillin G. Cells were rinsed three times with DME containing $0.1 \%$ BSA and incubated with ${ }^{125}$ I-apo E- $\beta$ VLDL $\left(3 \times 10^{6}\right.$ $\mathrm{cpm}, 200 \mathrm{ng} / \mathrm{ml}$, specific activity of $24,000 \mathrm{cpm} / \mathrm{ng}$ ) in the presence of the indicated antibodies for $3 \mathrm{~h}$ at $37^{\circ} \mathrm{C}$ in an incubator adjusted to $95 \%$ air $/ 5 \% \mathrm{CO}_{2}$. The medium was then removed, and adjusted to $15 \%$ TCA at $4^{\circ} \mathrm{C}$. After $1 \mathrm{~h}$, precipitated proteins were sedimented $(10,000 \mathrm{~g}, 15 \mathrm{~min})$, and the TCA-soluble counts released into the supernatant were quantitated by gamma counting. TCA-soluble $\mathrm{cpm}$ was divided by specific activity $(24,000 \mathrm{cpm} / \mathrm{ng})$ to determine amount of ${ }^{125} \mathrm{I}$-apo E- $\beta$ VLDL degraded. 


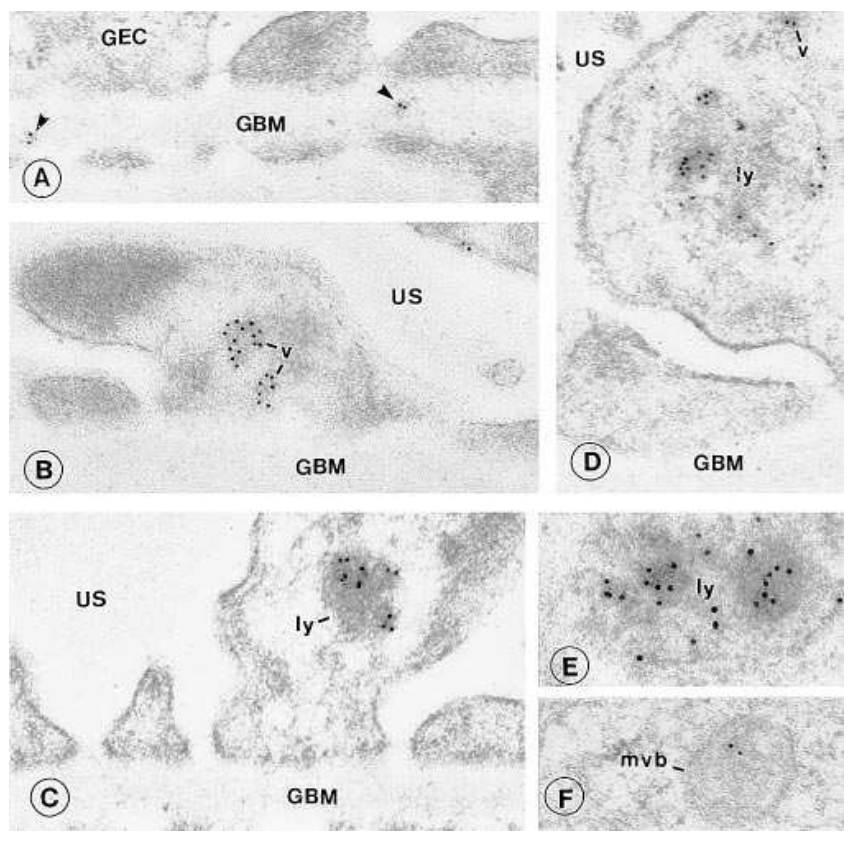

Figure 2. Localization of apo E in the GBM and endocytic system of podocytes from normal rat kidneys by indirect immunogold labeling. Ultrathin sections were prepared from Lowicryl-embedded kidneys and incubated sequentially with an anti-apo $\mathrm{E} \mathrm{mAb}$ and anti-mouse 10-nm gold conjugate. $(A)$ apo $\mathrm{E}$ is seen in small electron-dense granules in the GBM that may correspond to lipoprotein particles (arrowheads). $(B-D)$ Gold particles are found within endocytic vesicles $(v)$, lysosomes $(l y)$, and multivesicular bodies $(m v b)$ of podocytes. $U S$, Urinary space. GEC, Glomerular epithelial cell. $\times 18,000$.

\section{Results}

apo $E$ and apo $B$ are endocytosed by podocytes of normal kidneys. To determine if podocytes normally internalize apo $\mathrm{E}$ and apo B, glomeruli from control animals were analyzed for the presence of these proteins by immunoelectron microscopy. Minimal granular staining of glomeruli of normal rats has been observed by indirect immunofluorescence in a previous study (11). By immunoelectron microscopy, apo E was found occasionally within the GBM in association with electron-dense granules (Fig. $2 A$ ) and also within endocytic vesicles (Fig. $2 B$ ) and lysosomes (Figs. 2, $C-F$ ) of podocytes. apo B was found in clathrin-coated pits at the base of foot processes (Fig. 3, $A-C$ ), within intracellular vesicles (Fig. 3, $C$ and $D$ ), and occasionally

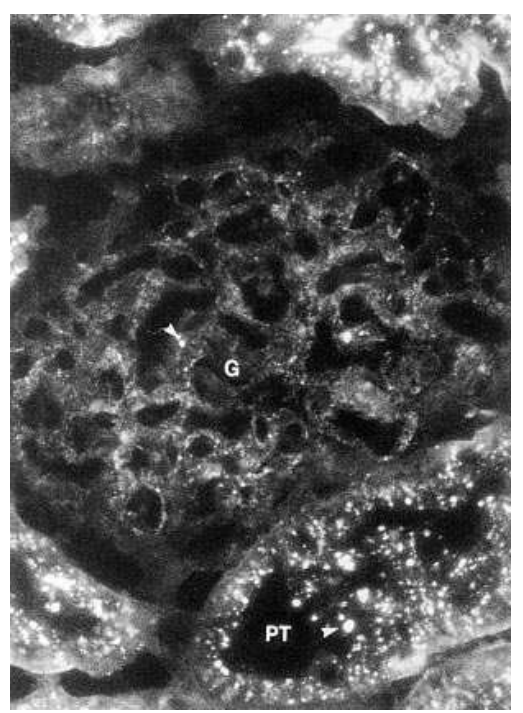

Figure 4. Localization of apo $\mathrm{E}$ by indirect immunofluorescence on a cryostat section of a kidney from a rat with $\mathrm{pHN}$ induced by injecting affinity-purified sheep antimegalin IgG $3 \mathrm{~d}$ before. apo $\mathrm{E}$ is detected in a granular pattern in peripheral capillary loops resembling the distribution of IDs. apo $\mathrm{E}$ is also found in lysosomes (arrowheads) of epithelial cells of the glomerulus $(G)$ and proximal tubule $(P T) . \times 600$.

associated with the endothelial cell surface (Fig. $3 C$ ) and the GBM (Fig. 3 D). These findings demonstrate that apo E- and apo B-containing lipoproteins or their fragments can cross the GBM and be endocytosed by podocytes, suggesting that uptake of lipoproteins occurs as a regular housekeeping function of the podocyte.

apo $E$ and apo $B$ accumulate within IDs of rats with $p H N$. To assess the fate of apo $\mathrm{E}$ and apo $\mathrm{B}$ in $\mathrm{pHN}$, affinity-purified antimegalin $\mathrm{IgG}$ was injected into normal rats (23) to induce $\mathrm{pHN}$, and the animals were killed 3 or $6 \mathrm{~d}$ after injection. By immunofluorescence, apo E (Fig. 4) and apo B (Fig. 6 A) were found in glomeruli of $\mathrm{pHN}$ rats in a granular distribution resembling that of IDs. By immunogold labeling, apo E (Fig. 5) and apo B (Fig. $6 B$ ) were localized within IDs, lysosomes, and multivesicular bodies of podocytes. As IDs do not show up well due to low contrast in the Lowicryl sections used for immunoelectron microscopy, their presence was confirmed by detecting the antigenic target megalin (Fig. 5, $D$ and $E$ ), which is found consistently in ID of $\operatorname{HN}(24,25)$. No labeling was seen in controls using an irrelevant primary antibody (data not shown). These results provide direct evidence that apo $\mathrm{E}$ and apo $\mathrm{B}$ accumulate within IDs of rats with $\mathrm{pHN}$ induced with monospecific antimegalin IgG.

Antimegalin and eluted glomerular IgGs inhibit the binding of megalin to apo E-enriched $\beta V L D L$. The presence of apo E and apo $\mathrm{B}$ within IDs of $\mathrm{pHN}$ rats induced with antimegalin
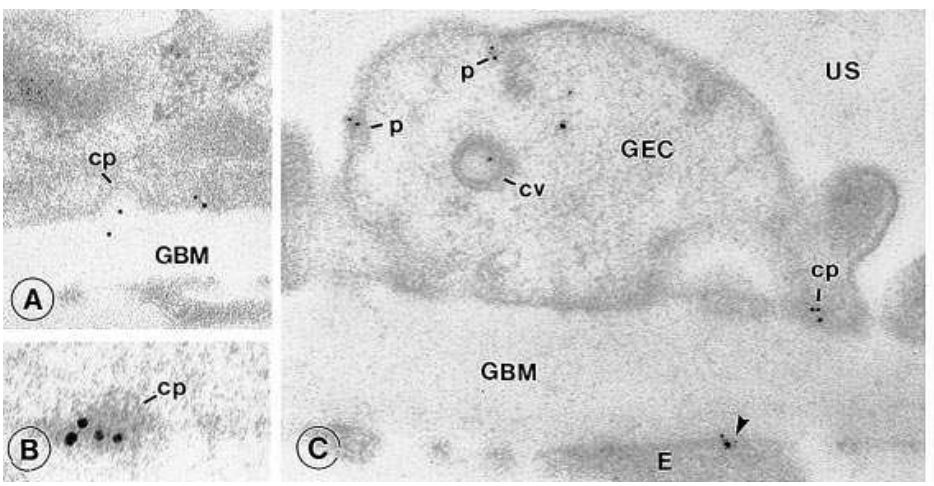

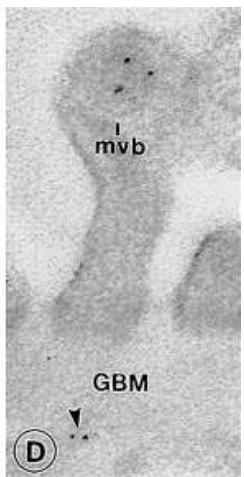

Figure 3. Localization of apo B in endocytic elements of normal rat kidney by indirect immunogold labeling. apo B is seen within the GBM $(A$ and $D)$, in coated pits on the basal $(c p)$ or lateral $(p)$ cell membrane, and in multivesicular bodies $(m v b)$ of podocytes $(G E C)$. US, Urinary space. $G E C$, Glomerular epithelial cell. $c v$, Coated vesicle. $\times 18,000$. 

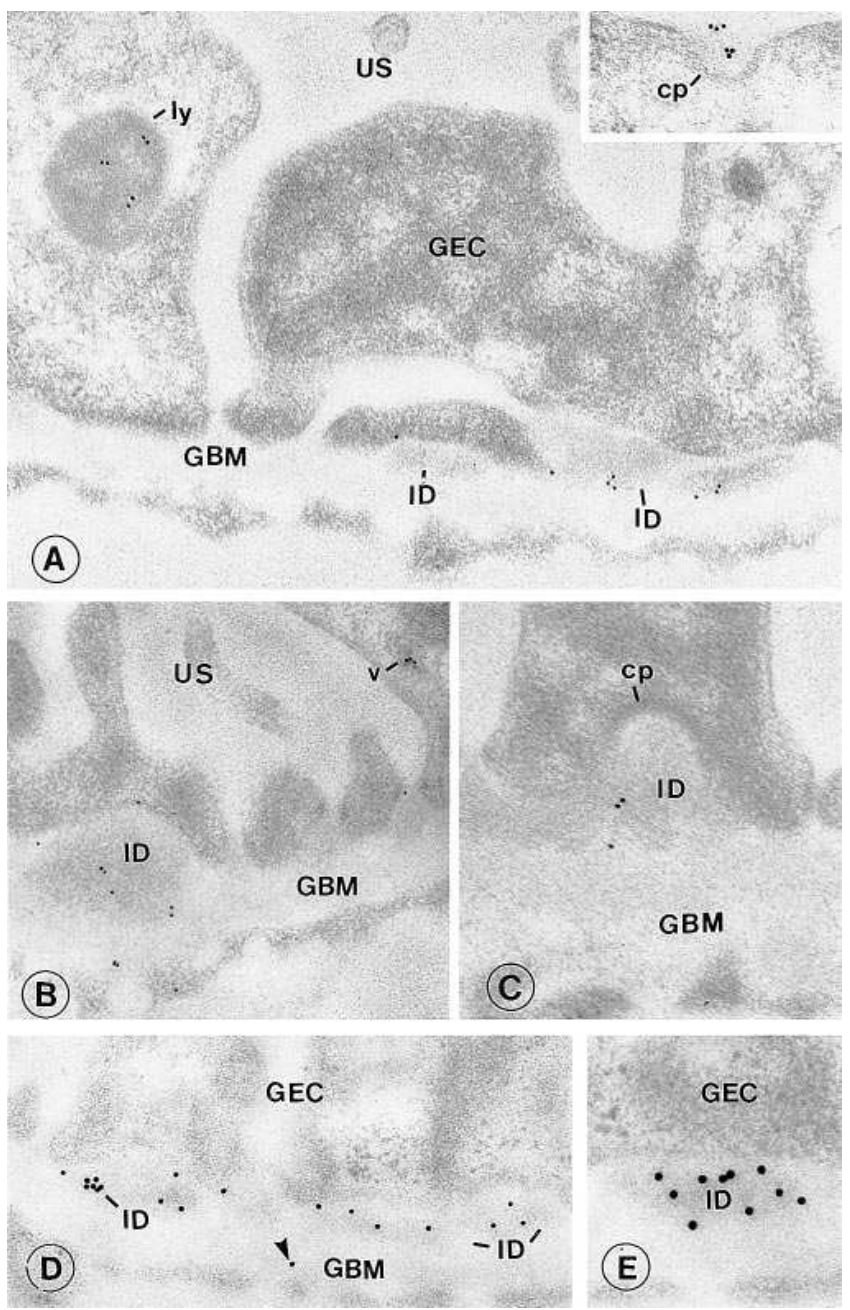

Figure 5. Localization of apo E in IDs in glomeruli of 3-d pHN rats by indirect immunogold labeling. Sections of Lowicryl-embedded kidneys of rats injected with affinity-purified sheep antimegalin $\mathrm{IgG}$ were incubated with anti-apo $\mathrm{E} \mathrm{mAb}$ followed by an anti-mouse 10nm gold conjugate. $(A-C)$ apo $\mathrm{E}$ is localized within subepithelial IDs and on the base of the foot processes in association with IDs. It is also found in lysosomes $(l y)$ and small vesicles $(v)$ within glomerular epithelial cells $(G E C)$ and in clathrin-coated pits $(c p)$ on the urinary surface $(U S)$ of glomerular epithelial cells $(A$, inset). ( $D$ and $E$ ) The presence of subepithelial IDs is verified by immunogold labeling with affinity-purified rabbit antimegalin $\operatorname{IgG} . A, B$, and $D, \times 18,000 ; C, E$, and inset in $A, \times 30,000$.

IgG suggested that the antibodies might inhibit binding and uptake of these ligands. Next, we tested if antimegalin antibodies are able to inhibit directly ${ }^{125}$ I-megalin binding to immobilized apo E- $\beta$ VLDL using a solid-phase assay (26). Both the affinity-purified sheep and rabbit antimegalin IgGs inhibited the binding of ${ }^{125} \mathrm{I}$-megalin to apo E- $\beta$ VLDL by $>80 \%$ (Fig. 7). Moreover, the sheep and rabbit antimegalin IgGs and antimicrovillar $\mathrm{IgG}$ eluted from glomeruli of $\mathrm{pHN}$ rats also inhibited the binding of ${ }^{125} \mathrm{I}$-megalin to apo E- $\beta$ VLDL by $50-75 \%$. By contrast, antimegalin monoclonal 20B (16), which failed to induce IDs, also failed to inhibit this interaction. These data show that all antimegalin IgGs capable of inducing IDs and all preparations of $\operatorname{IgG}$ eluted from glomeruli of rats injected with different antimegalin IgGs are capable of inhibiting the binding of apo E- $\beta$ VLDL to megalin. This suggests that the accumulation of apo E and apo B within IDs could be due to the inhibition of uptake of these ligands by megalin.

Internalization of apo $E-\beta V L D L$ by megalin is inhibited by eluted glomerular antibodies in vivo. We next tested if the antibodies eluted from glomeruli of rats with $\mathrm{pHN}$ are able to inhibit the endocytosis of apo E- $\beta$ VLDL. To this end, we incubated rat L2 cells, a cell line known to express megalin $(13,22$, 27 ), with radioiodinated apo E- $\beta$ VLDL in the presence of varying amounts of antimegalin $\mathrm{IgG}, \mathrm{IgG}$ eluted from glomeruli of $\mathrm{pHN}$ rats, or nonimmune $\mathrm{IgG}$ at $37^{\circ} \mathrm{C}$. We then determined the amount of ${ }^{125}$ I-apo E- $\beta$ VLDL degraded, by quantitating the TCA-soluble radioactivity released into the medium after $3 \mathrm{~h}$ of incubation. As shown in Fig. 8, cells incubated with nonimmune $\operatorname{IgG}$ took up and degraded considerable amounts of apo E- $\beta$ VLDL, as indicated by release of nonTCA-precipitable radioactivity. By contrast, when cells were incubated with either antimegalin IgG or glomerular eluted antibodies, the degradation of ${ }^{125}$ I-apo E- $\beta$ VLDL was inhibited in a concentration-dependent manner. These results demonstrate that antibodies eluted from glomeruli of $\mathrm{pHN}$ rats induced with antimegalin $\operatorname{IgG}$ are able to inhibit the binding and internalization of apo E-enriched $\beta$ VLDL by megalin in vivo.

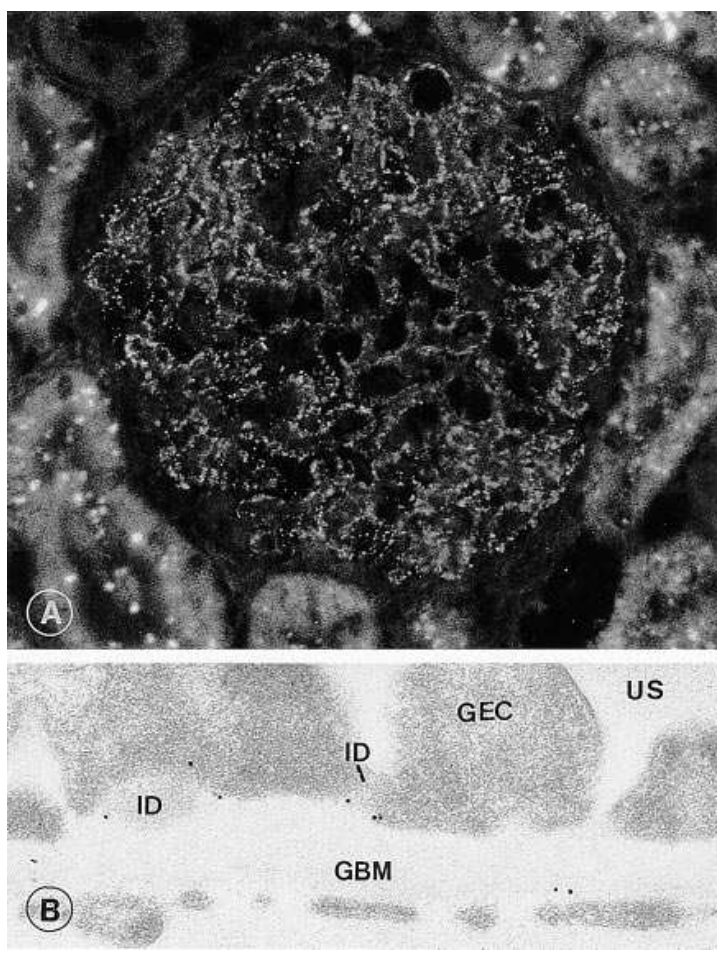

Figure 6. Localization of apo B to ID in kidneys of $\mathrm{pHN}$ rats injected with affinity-purified sheep antimegalin IgG. Specimens processed as in Fig. 4 for indirect immunofluorescence $(A)$ or as in Fig. 5 for immunogold labeling $(B)$. The overall distribution of apo $\mathrm{B}$ is similar to that of apo E (see Figs. 4 and 5). (A) apo B is concentrated in peripheral capillary loops in a fine granular pattern, similar to the distribution of ID. It is also seen in lysosomes of proximal tubule cells. $(B)$ By immunoelectron microscopy, apo B is found in subepithelial IDs. $U S$, Urinary space. $G E C$, Glomerular epithelial cell. $A, \times 600 ; B, \times 18,000$. 


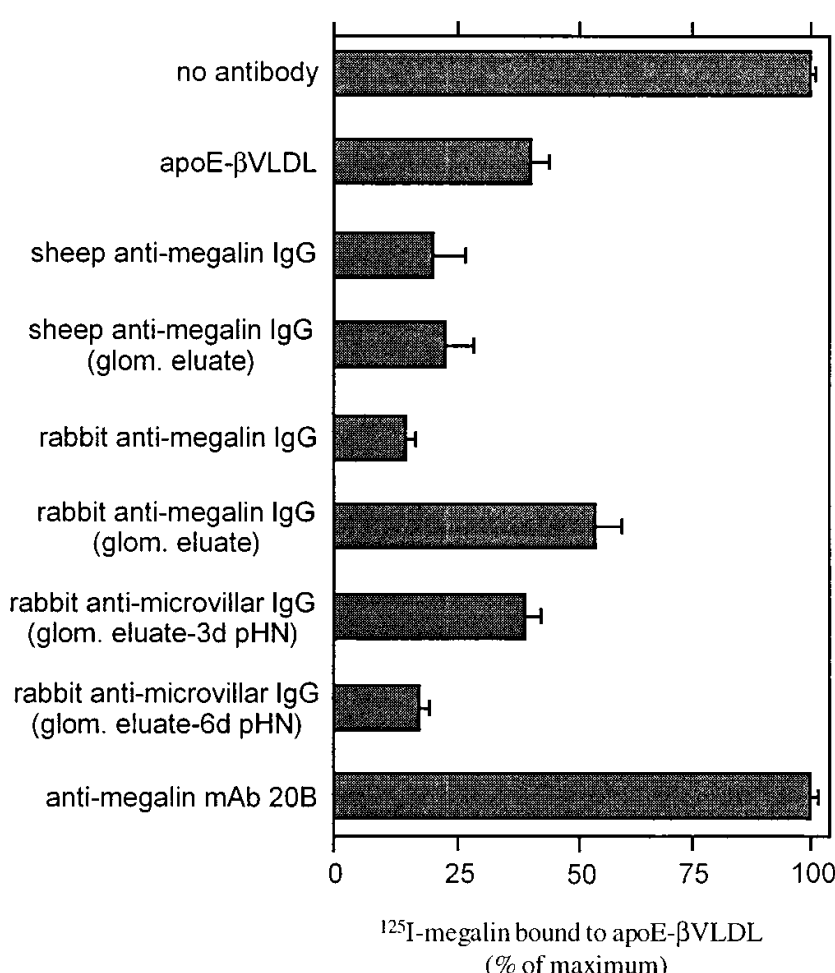

Figure 7. $\mathrm{IgG}$ eluted from glomeruli of $\mathrm{pHN}$ rats inhibits the binding of ${ }^{125}$ I-megalin to immobilized apo E- $\beta$ VLDL. Results are expressed as percentage of the total ${ }^{125} \mathrm{I}$-megalin bound to apo E- $\beta \mathrm{VLDL}$ in the absence of inhibitors. Sheep and rabbit antimegalin IgG used to induce $\mathrm{pHN}$ and the corresponding $\mathrm{IgG}$ eluted from isolated glomeruli of $\mathrm{pHN}$ rats all effectively inhibited the binding of ${ }^{125} \mathrm{I}$-megalin to apo E- $\beta$ VLDL. Both the 3- and 6-d glomerular eluates from the $\mathrm{pHN}$ rats induced with rabbit antimicrovillar IgG also inhibited binding. Binding was also inhibited by apo E- $\beta$ VLDL. The non-ID-inducing $\mathrm{mAb}$ 20B failed to block the receptor-ligand interaction. The concentration of each $\mathrm{IgG}$ preparation in this assay was adjusted to equal titers as determined by indirect immunofluorescence on cryosections of normal rat kidney. Total IgG concentrations of glomerular eluates (see Methods) were determined by an ELISA. Experiments were performed twice in duplicate. Bars indicate SDs, consistently $<10 \%$.

\section{Discussion}

Knowledge of the molecular mechanisms of glomerular capillary wall damage and resulting proteinuria in membranous nephropathy is less advanced than our understanding of the pathogenesis of ID formation (for review, see references 5 and 25). It is established that C5b-9 complement membrane attack complexes form within IDs (28), and that their insertion into cell membranes of podocytes (29) triggers the development of proteinuria. The generation of reactive oxygen species (ROS) within the glomerulus has been identified as a critical C5b-9dependent step (30). ROS were found to induce local LPO, forming reactive compounds that damage GBM matrix proteins, particularly type IV collagen (12). This sequence of events appears to be a major pathogenic mechanism leading to damage to the GBM in $\mathrm{pHN}$, because proteinuria can be abrogated by treatment with the potent LPO-inhibitor, probucol (12). These findings raised the question as to the source of polyunsaturated fatty acids required for LPO. We hypothe- sized that lipoproteins originating from the plasma could serve as a source for these lipids (11), similar to their role in atherosclerotic lesions (31), and, in keeping with this idea, we showed that apo B and apo E were localized within IDs of rats with pHN (11). In addition, apo B extracted from isolated glomeruli in pHN showed signs of oxidative damage, such as fragmentation and malondialdehyde adduct formation (11).

Collectively, these recent studies suggest that the accumulation of apo E- and apo B-containing lipoproteins within IDs could provide the necessary environment for LPO and play a critical role in the development of proteinuria in HN. Since megalin is a receptor for apo E (10) and B100 (9), we have investigated if antimegalin $\mathrm{IgG}$, when injected into rats to induce $\mathrm{pHN}$, inhibits ligand binding to the receptor during the formation of IDs, which in turn results in an accumulation of apo Eand apo B-containing lipoproteins and/or their fragments (11). In this study, we provide evidence that podocytes internalize apo $\mathrm{E}$ and apo $\mathrm{B}$ as a normal housekeeping function, and that the injection of antimegalin $\mathrm{IgG}$ results in the deposition of these lipoprotein carriers within IDs. Using a solid-phase binding assay, we showed further that IgG fractions prepared from several independent $\mathrm{pHN}$-inducing sera are capable of inhibiting the binding of apo E- $\beta$ VLDL to purified megalin. Moreover, the antimegalin IgG eluted from glomeruli of $\mathrm{pHN}$ rats also inhibited strongly both ligand binding to megalin and megalin-mediated ligand internalization in a cultured cell line. From these findings, we conclude that antibody binding to megalin during the induction of $\mathrm{pHN}$ interferes with the bind-

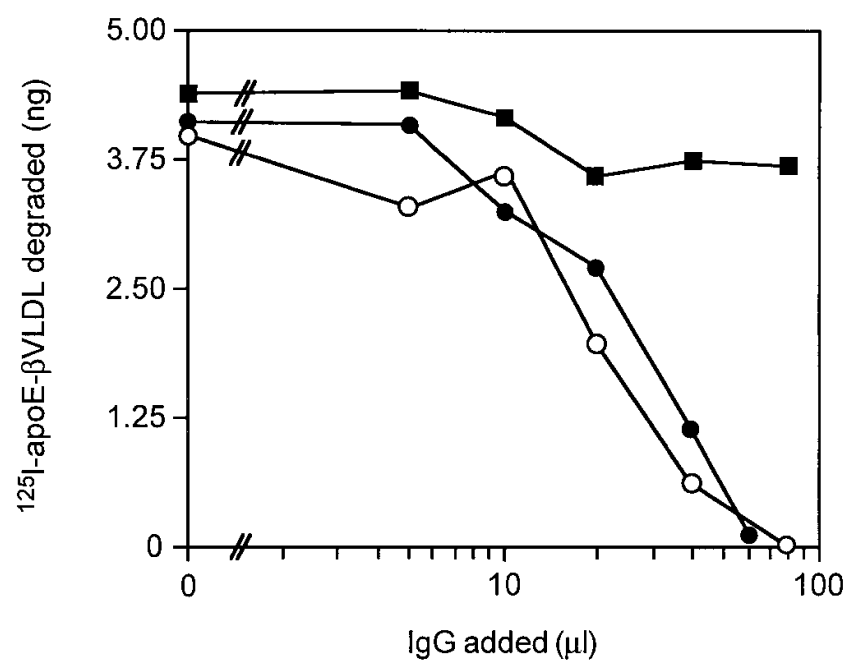

Figure 8. IgG eluted from glomeruli of $\mathrm{pHN}$ rats inhibits megalinmediated internalization and degradation of ${ }^{125} \mathrm{I}$-apo E- $\beta$ VLDL. Cultured L2 rat yolk sac cells that express megalin were incubated with ${ }^{125} \mathrm{I}$-apo E- $\beta \mathrm{VLDL}$ in the presence of varying amounts of either rabbit antimegalin $\operatorname{IgG}(\bullet, 3 \mu \mathrm{g} / \mathrm{ml})$, IgG eluted from glomeruli of $\mathrm{pHN}$ rats $(O, 10 \mu \mathrm{g} / \mathrm{ml})$ injected with rabbit antimegalin $\mathrm{IgG}$, or nonimmune $\operatorname{IgG}(\mathbf{\square}, 3 \mu \mathrm{g} / \mathrm{ml})$. After $3 \mathrm{~h}$, the culture medium was adjusted to $15 \%$ TCA to precipitate undegraded proteins, and the TCA-soluble radioactivity released into the supernatant was measured to quantitate intracellular degradation. Both antimegalin and glomerular eluted IgG inhibited the internalization and degradation of radiolabeled apo E- $\beta$ VLDL in a concentration-dependent manner. Nonimmune $\mathrm{IgG}$ showed no effect on intracellular degradation of ${ }^{125}$ I-apo E- $\beta$ VLDL. Experiments were performed twice in duplicate. $\mathrm{SD}$ of replicate points was consistently $<5 \%$. 
ing and internalization of apo E- and apo B-containing lipoproteins by the receptor on the podocyte cell surface. Therefore, these results provide a logical explanation for the series of events in HN that leads to the accumulation of apos within IDs and the GBM.

These findings are consistent with recent studies by us (14) and others (32) in which a pathogenic epitope has been identified in megalin that binds IgGs eluted from glomeruli of $\mathrm{pHN}$ rats, and therefore is directly involved in the development of $\mathrm{pHN}$. Interestingly, this epitope was found to reside in the fifth cysteine-rich domain of the second cluster of ligand-binding motifs (14) and to overlap with a recently identified apo E- $\beta$ VLDL binding site on megalin (33). Thus, the binding sites for both the eluted glomerular IgGs and apo E- $\beta$ VLDL are located within this short 46-amino acid domain of megalin.

Before the availability of monospecific antibodies, $\mathrm{pHN}$ was induced by injection of polyspecific $\mathrm{IgG}$ raised against crude kidney cortical fractions, such as Fx1A (34) or isolated rat microvilli (35). These sera contained IgGs directed not only against megalin, but also against complement C5b-9-activating lipids (23) and several other microvillar constituents. Injection of these mixed $\mathrm{IgG}$ into rats resulted in ID formation, capillary damage, and heavy proteinuria, which could account for the penetration of large lipoprotein particles through the GBM and their accumulation within the GBM and IDs. By contrast, in this study, we have induced IDs by injecting affinity-purified antimegalin IgG without inducing capillary damage (23), and have found a similar deposition of apo B and apo E within IDs. Our results demonstrate that binding of ID-forming antimegalin $\mathrm{IgG}$ is sufficient for accumulation of lipoproteins within IDs in vivo and does not require capillary damage or C5b-9 activation. However, it remains to be determined how such large lipoprotein particles or their fragments are able to penetrate the GBM without the gross GBM damage that occurs upon activation of the complement.

Are nephritogenic $\mathrm{HN}$ antibodies in general capable of interfering with megalin-ligand interactions, and is this property a prerequisite for the stability and growth of IDs and thus for progression of the disease? Accumulation of megalin-immune complexes in the lamina rara externa of the GBM can be explained by inhibition of endocytosis, which occurs normally when ligands bind to megalin. It seems likely that rapid shedding of the immune complexes from the podocyte cell surface and their immobilization within the GBM (24) would make it impossible for these cells to internalize efficiently and to clear the complexes by endocytosis. At present, no experimental answers to these questions are available.

An important finding from this study indicates that one physiological function of megalin in podocytes is receptormediated uptake of apo E- and apo B-containing lipoproteins. It is intriguing that all ID-forming antimegalin $\mathrm{IgG}$ tested to date inhibit specifically the binding of these lipoproteins to megalin. This may suggest that biologically active sites on proteins, such as those for ligand binding, could serve preferentially as autoantigenic targets, as proposed by the recent finding for autoantigens in systemic lupus erythematodes (36).

In $\mathrm{pHN}$, ID-forming antibodies are apparently a crossroad for pathogenic mechanisms of ID formation and proteinuria, in that the antibody-mediated inhibition of lipoprotein binding to megalin results in their accumulation within IDs, where they provide fatty acids needed for LPO, a major cause for GBM damage and proteinuria in pHN (12). Similar pathogenic mechanisms may also operate within ID in human membranous nephropathy, as apo E and B100 have been found in human glomeruli by immunofluorescence (37) and by immunoelectron microscopy (our unpublished results).

\section{Acknowledgments}

We wish to thank Jennifer Pattison for preparing the purified apo E- $\beta$ VLDL used in this study.

This work was supported by the SFB "Tissue Damage and Repair" from the Fonds zur Förderung der Wissenschaftlichen Forschung (to D. Kerjaschki), National Institutes of Health research grant DK-17724 (to M.G. Farquhar), and National Heart, Lung, and Blood Institute SCOR grant HL-14197 (to J.L. Witztum).

\section{References}

1. Schwartz, M.M. 1992. Membranous glomerulonephritis. In Pathology of the Kidney. R.H. Hepinstall, editor. Little, Brown and Company, Boston/Toronto/London. 559-626.

2. Schöndorff, D., U. Dendorfer, V. Brumberger, and C. Keunecke. 1995. Limitations of therapeutic approaches to glomerular diseases. Kidney Int. 50: S19-S25.

3. Heymann, W., D.B. Hackel, S. Harwood, S.G.F. Wilson, and J.L.P. Hunter. 1959. Production of the nephrotic syndrome in rats by Freund's adjuvants and rat kidney suspensions. Proc. Soc. Exp. Biol. Med. 100:660-664.

4. Cavallo, T. 1994. Membranous nephropathy. Insights from Heymann nephritis. Am. J. Pathol. 144:651-658.

5. Kerjaschki, D., and T.J. Neale. 1996. Molecular mechanisms of glomerular injury in rat experimental membranous nephropathy (Heymann nephritis). J. Am. Soc. Nephrol. 7:2518-2526.

6. Farquhar, M.G., D. Kerjaschki, M. Lundstrom, and R.A. Orlando. 1994. gp330 and RAP: the Heymann nephritis antigenic complex. Ann. NY Acad. Sci. 737:96-113.

7. Saito, A., S. Pietromonaco, A.K. Loo, and M.G. Farquhar. 1994. Complete cloning and sequencing of rat gp330/"megalin," a distinctive member of the low density lipoprotein receptor gene family. Proc. Natl. Acad. Sci. USA. 91:9725-9729.

8. Raychowdhury, R., J.L. Niles, R.T. McCluskey, and J.A. Smith. 1989. Autoimmune target in Heymann nephritis is a glycoprotein with homology to the LDL receptor. Science (Wash. DC). 244:1163-1165.

9. Stefansson, S., D.A. Chappell, K.M. Argraves, D.K. Strickland, and W.S Argraves. 1995. Glycoprotein 330/low density lipoprotein receptor-related protein-2 mediates endocytosis of low density lipoproteins via interaction with apolipoprotein B100. J. Biol. Chem. 270:19417-19421.

10. Willnow, T.E., J.L. Goldstein, K. Orth, M.S. Brown, and J. Herz. 1992. Low density lipoprotein receptor-related protein and gp330 bind similar ligands, including plasminogen activator-inhibitor complexes and lactoferrin, an inhibitor of chylomicron remnant clearance. J. Biol. Chem. 267:26172-26180.

11. Exner, M., M. Susani, J.L. Witztum, A. Hovorka, L.K. Curtiss, S. Spitzauer, and D. Kerjaschki. 1996. Lipoproteins accumulate in immune deposits and are modified by lipid peroxidation in passive Heymann nephritis. Am. J. Pathol. 149:1313-1320.

12. Neale, T.J., P.P. Ojha, M. Exner, H. Poczewski, B. Ruger, J.L. Witztum, P. Davis, and D. Kerjaschki. 1994. Proteinuria in passive Heymann nephritis is associated with lipid peroxidation and formation of adducts on type IV collagen. J. Clin. Invest. 94:1577-1584.

13. Orlando, R.A., and M.G. Farquhar. 1993. Identification of a cell line that expresses a cell surface and a soluble form of the gp330/receptor-associated protein (RAP) Heymann nephritis antigenic complex. Proc. Natl. Acad. Sci. USA. 90:4082-4086.

14. Saito, A., H. Yamazaki, K. Rader, A. Nakatani, R. Ullrich, D. Kerjaschki, R.A. Orlando, and M.G. Farquhar. 1996. Mapping rat megalin: the second cluster of ligand binding repeats contains a 46-amino acid pathogenic epitope involved in the formation of immune deposits in Heymann nephritis. Proc. Natl. Acad. Sci. USA. 93:8601-8605.

15. Kerjaschki, D., and M.G. Farquhar. 1982. The pathogenic antigen of Heymann nephritis is a membrane glycoprotein of the renal proximal tubule brush border. Proc. Natl. Acad. Sci. USA. 79:5557-5581.

16. Miettinen, A., G. Dekan, and M.G. Farquhar. 1990. Monoclonal antibodies against membrane proteins of the rat glomerulus. Immunochemica specificity and immunofluorescence distribution of the antigens. Am. J. Pathol. 137:929-944.

17. Orlando, R.A., D. Kerjaschki, H. Kurihara, D. Biemesderfer, and M.G. Farquhar. 1992. gp330 associates with a $44-\mathrm{kDa}$ protein in the rat kidney to form the Heymann nephritis antigenic complex. Proc. Natl. Acad. Sci. USA. 89: 6698-6702.

18. Kerjaschki, D., and M.G. Farquhar. 1983. Immunocytochemical local- 
ization of the Heymann nephritis antigen (GP330) in glomerular epithelial cells of normal Lewis rats. J. Exp. Med. 157:667-686.

19. Orlando, R.A., D. Kerjaschki, and M.G. Farquhar. 1995. Megalin (gp330) possesses antigenic epitopes capable of inducing passive Heymann nephritis independent of the nephritogenic epitope in RAP.J. Am. Soc. Nephrol. 6:61-67.

20. Armbruster, B.L., E. Carlemalm, R. Chiovetti, R.M. Gravioti, J.A. Hobot, E. Kellenberger, and W. Vilinger. 1982. Specimen preparation for electron microscopy using low temperature embedding resin. J. Microsc. (Oxf.). 126:7792.

21. Horvat, R., A. Hovorka, G. Dekan, H. Poczewski, and D. Kerjaschki. 1986. Endothelial cell membranes contain podocalyxin - the major sialoprotein of visceral glomerular epithelial cells. J. Cell Biol. 102:484-491.

22. Lundstrom, M., R.A. Orlando, M.S. Saedi, L. Woodward, H. Kurihara, and M.G. Farquhar. 1993. Immunocytochemical and biochemical characterization of the Heymann nephritis antigenic complex in rat L2 yolk sac cells. Am. J. Pathol. 143:1423-1435.

23. Susani, M., M. Schulze, M. Exner, and D. Kerjaschki. 1994. Antibodies to glycolipids activate complement and promote proteinuria in passive Heymann nephritis. Am. J. Pathol. 144:807-819.

24. Kerjaschki, D., A. Miettinen, and M.G. Farquhar. 1987. Initial events in the formation of immune deposits in passive Heymann nephritis. gp330-antigp330 immune complexes form in epithelial coated pits and rapidly become attached to the glomerular basement membrane. J. Exp. Med. 166:109-128.

25. Farquhar, M.G., A. Saito, D. Kerjaschki, and R.A. Orlando. 1995. The Heymann nephritis antigenic complex: megalin (gp330) and RAP. J. Am. Soc. Nephrol. 6:35-47.

26. Orlando, R.A., and M.G. Farquhar. 1994. Functional domains of the receptor-associated protein (RAP). Proc. Natl. Acad. Sci. USA. 91:3161-3165.

27. Czekay, R.P., R.A. Orlando, L. Woodward, M. Lundstrom, and M.G. Farquhar. 1997. Endocytic trafficking of megalin/RAP complexes: dissociation of the complexes in late endosomes. Mol. Biol. Cell. 8:517-532.

28. Couser, W.G. 1985. Mechanisms of glomerular injury in immune-complex disease. Kidney Int. 28:569-583.

29. Kerjaschki, D., M. Schulze, S. Binder, R. Kain, P. Ojha, M. Susani, R. Horvat, P.J. Baker, and W.G. Couser. 1989. Transcellular transport and membrane insertion of the C5b-9 membrane attack complex of complement by glomerular epithelial cells in experimental membranous nephropathy. J. Immunol. 143:546-552.

30. Shah, S.V. 1989. Role of reactive oxygen metabolites in experimental glomerular disease. Kidney Int. 36:1093-1106.

31. Witztum, J.L. 1994. The oxidation hypothesis of atherosclerosis. Lancet 344:793-795.

32. Raychowdhury, R., G. Zheng, D. Brown, and R.T. McCluskey. 1996. Induction of Heymann nephritis with a gp330/megalin fusion protein. Am. J. Pathol. 148:1613-1623.

33. Orlando, R.A., M. Exner, R.P. Czekay, H. Yamazaki, A. Saito, R. Ullrich, D. Kerjaschki, and M.G. Farquhar. 1997. Identification of the second clus ter of ligand binding repeats in megalin as a site for receptor-ligand interactions. Proc. Natl. Acad. Sci. USA. 94:2368-2373.

34. Edgington, T.S., R.J. Glassock, and F.J. Dixon. 1968. Autologous immune-complex pathogenesis of experimental allergic glomerulonephritis. Science (Wash. DC). 155:1432-1434.

35. Miettinen, A., T. Tornroth, I. Tikkanen, I. Virtanen, and E. Linder. 1980. Heymann nephritis induced by kidney brush border glycoproteins. $L a b$. Invest. 43:547-555.

36. Tsai, W.M., G. Roos, T.E. Hugli, and E.M. Tan. 1992. Influence of free thiol group(s) on autoantibody-defined epitope of proliferating cell nuclear antigen. J. Immunol. 149:2227-2233.

37. Sato, H., S. Suzuki, H. Kobayashi, S. Ogino, A. Inomata, and M. Arkawa. 1991. Immunohistological localization of apolipoproteins in the glomeruli in renal disease: specifically apo B and apo E. Clin. Nephrol. 36:127-133. 